\title{
Linking participants in school-based sport programs to community clubs
}

\author{
Rochelle M. Eime*, Warren R. Payne
}

School of Human Movement and Sport Sciences, University of Ballarat, Australia

\section{Introduction}

Participation in regular physical activity, including sport, impacts positively on physical, mental and

* Corresponding author.

E-mail address: r.eime@ballarat.edu.au (R.M. Eime). social health. ${ }^{1,2}$ However, an alarming number of people, including children and youth, are not sufficiently active to receive these benefits. ${ }^{3-5}$

Schools are a setting for introducing children and youth to sport and establishing foundation motor skills and encouraging sport participation, ${ }^{2}$ which can give children and youth the confidence 
to explore and join community-based sport clubs. ${ }^{6,7}$ However, the integration between school and community club-based sport is lacking. ${ }^{2}$ The development of school-community sport links is widely advocated for reducing the public health burden of chronic diseases associated with sedentary lifestyles. ${ }^{4,6,8-11}$

Community sports clubs play an important role in providing an institutional framework for sport activities throughout the world. ${ }^{12,13}$ Engagement in community club sport can reduce aggressive behaviour, assist in the acquisition of confidence, competence and a sense of belonging, new friendships and improved social connectedness. ${ }^{13-18}$ Adolescents participating in sports clubs have been shown to be more likely to be physical active into adulthood. ${ }^{14,15,19}$ In addition to a public health perspective, organisations that administer and govern sport have a vested interest in reversing the decline in youth sport participation. 7,20

Notwithstanding these potential personal and community benefits, the factors affecting the transfer of participants in school-based sport participation programs into community-based sporting clubs have not been explored, and no structures to promote the transfer of youth into communitybased sport have been established and promoted.

The aim of this study was to explore the structural links between participation in programs conducted in schools and participation in community sporting clubs, with a view to providing guidance to key sport, education and health stakeholders regarding strategies to maximise this transfer.

\section{Methods}

The setting for this study was the state of Victoria, Australia, where State Sports Governing Organisations (SSGOs) are funded by a government-funded health promotion organisation (Victorian Health Promotion Foundation, VicHealth) to develop and deliver school- and community-based sports participation programs to promote community-level sports participation and wellbeing. ${ }^{21,22}$ Each SSGOs is responsible for the administration and development of a sport and governance of affiliated community sporting clubs.

This study was conducted during 2005. Three methodologies were utilised to obtain data at the sports organisation and school program level: a web-based survey; focus group discussions; and a program case study investigation. The study was approved by the University Human Research Ethics Committee with the condition that individual sporting organisations were not publicly identified.
Each VicHealth-funded SSGO $(n=49)$ was asked to complete a web-based survey in 2005, to investigate the type of settings where programs were delivered. The responses were analysed using SPSS $^{T M}$ software.

Two focus group discussions were held with 15 representatives from eight SSGOs: four randomly selected 'large' and four 'small' (based on their VicHealth funding and size of membership). The selected large SSGOs received funding for 3 years of between AUS $\$ 285,000$ and $\$ 750,000$ per year; the small SSGOs received $\$ 130,000$ each per year. The group discussions focused upon the structure of the SSGO-delivered programs; their reasons for delivering programs within school settings; and the link between participation in school-based programs and local sports clubs.

A SSGO program delivered in a school was randomly selected from VicHealth funded programs. The program (from a 'small' SSGO) was delivered by SSGO staff throughout metropolitan Melbourne and rural Victoria in 46 schools to 5302 students in 2005. Four parents, three teachers and one parent/teacher present at a program participation session were interviewed. Interviewees were drawn from six primary schools that had been involved with the program over a period of 1-6 years. An interview was also conducted with the program coordinator from the selected SSGO. The interviews sought to understand, at the grassroots level, the link between the program and local sports clubs, including the barriers and facilitators to continued local participation. Interviews were audiotaped and transcribed. Key themes were identified using content analysis. ${ }^{23}$

\section{Results}

The web-based survey was completed by 44 of the 49 SSGOs $(89.8 \%)$. Results indicated that the SSGOs often utilise the school setting for program delivery ( $n=26,59.1 \%$ of responding SSGOs). From the 100 VicHealth funded SSGO delivered programs (average 2.3 programs per SSGO), half of the 85 , for which a response was provided $(n=43$, $50.6 \%$ ), were conducted within a school setting, second only to a community club setting $(n=67$, $78.8 \%)$.

Table 1 provides a summary of the findings obtained from the focus group discussions about SSGO-delivered school-based programs links with clubs. The primary reason reported for delivering sport programs in schools was to raise awareness about, and develop interest in, their sport: "The reason for doing school clinics is not about getting 
Table 1 Structure of SSGO, school delivered sports programs

\begin{tabular}{|c|c|c|}
\hline Theme & Sub-theme & Response $(n=15)^{\mathrm{a}}$ \\
\hline \multirow{4}{*}{ School programs } & & $\begin{array}{l}\text { Not about membership } \\
\text { Providing visibility for your sport } \\
\text { Generates interest in sport } \\
\text { Teach our sport to the school teachers }\end{array}$ \\
\hline & Reasons & $\begin{array}{l}\text { Want sport taught well, as it is critical to } \\
\text { have basic skills for long-term participation } \\
\text { Objective is qualitative not quantitative } \\
\text { numbers } \\
\text { About exposure } \\
\text { Encourages children into sport in general } \\
\text { Raise awareness of your sport }\end{array}$ \\
\hline & General & $\begin{array}{l}\text { Aim should be to have children active in } \\
\text { school, to participate in any sport } \\
\text { Not a good investment } \\
\text { Some sports programs allow schools to } \\
\text { check-off physical activity and educational } \\
\text { outcomes } \\
\text { Schools welcome sports, but sport does not } \\
\text { necessarily gain membership }\end{array}$ \\
\hline & Bring students to the sport & $\begin{array}{l}\text { We take schools to our sports clubs } \\
\text { Allows us to link the students to clubs } \\
\text { Allows tracking of students in clubs }\end{array}$ \\
\hline \multirow[t]{2}{*}{ Linking school program to clubs } & General & $\begin{array}{l}\text { Need clubs local to the schools } \\
\text { Very hard to make the link } \\
\text { Difficult to get clubs to adopt a school }\end{array}$ \\
\hline & Barriers & $\begin{array}{l}\text { Difficult for volunteers to assist with } \\
\text { programs during school time } \\
\text { Parents not wanting to commit to clubs on } \\
\text { weekends } \\
\text { It is a long way from awareness to } \\
\text { participation }\end{array}$ \\
\hline \multirow{3}{*}{ Sport participation in schools } & & $\begin{array}{l}\text { Should be role of Education Department and } \\
\text { not the SSGOs }\end{array}$ \\
\hline & Role of SSGOs & $\begin{array}{l}\text { Government expects SSGOs to take these } \\
\text { school programs on board and deliver them } \\
\text { SSGOs are not funded by government to run } \\
\text { school programs } \\
\text { We do not have the resources, we must } \\
\text { prioritise our service to our members } \\
\text { Needs to be recognition of what the } \\
\text { expectations are }\end{array}$ \\
\hline & Recommendation & $\begin{array}{l}\text { VicHealth lobby for sport infrastructure to } \\
\text { cover basic skill development in schools }\end{array}$ \\
\hline
\end{tabular}

\footnotetext{
${ }^{a}$ Number of respondents.
}

membership, its about providing the visibility of your sport and something a little bit special, its not about membership any more for us in that regard." These programs also provided SSGOs with the opportunity to train teachers in the delivery of their particular sport, and to involve school children in physical activity in general: "We should be saying that we want the kids to be active at school, participate in any sort of sport." However, focus group participants felt that providing these opportunities to students was highly resourcedependent and was the responsibility of the Victorian Department of Education and Training, rather than SSGOs: "We do not need SSGOs and 
their overworked volunteers running into schools to run clinics. That shouldn't be the role of the SSGOs, unless we are going to be funded to develop recreational programs." It was felt that targeting programs within schools was not a good investment as a means to promote club membership.

Barriers to linking students to clubs included the difficulty in tracking students, and in having club volunteers assist with the program delivery during school time. Concerns regarding engagement of volunteers were reflected in the statement, "Our problem is if we want to run program in schools and they do want to run them in school hours, is there anyone available from the club who can actu- ally be there, they're working themselves, so that becomes a difficulty." Some SSGOs took the students to the clubs to deliver the programs and this strategy was thought facilitate club participation and membership.

The discussions also revealed that the capacity of the SSGOs to deliver the school-based programs was directly related to the size of the SSGO. That is, 'large' SSGOs had a far greater capacity to deliver larger programs or programs to a wider audience than 'small' SSGOs. However, the issues relating to the actual delivery of school-based programs and the linking of these participants to clubs were common across the two groups.

Table 2 Linking program participants to local opportunities

\begin{tabular}{|c|c|c|}
\hline Theme & Sub-theme & $\begin{array}{l}\text { Combined responses of the SSGO }{ }^{\mathrm{a}} \text {, teachers and/or } \\
\text { parents }^{\mathrm{b}}\end{array}$ \\
\hline \multirow[t]{4}{*}{ Facilitators $(n=27)$} & Interest and awareness $(n=12)$ & $\begin{array}{l}\text { Child interest and parent present at introductory session } \\
(n=5) \\
\text { Child interest }(n=4) \\
\text { Club receptiveness to new members (SSGO) } \\
\text { Having a friend as a club member (SSGO) } \\
\text { Bring-a-friend activity days at club (SSGO) }\end{array}$ \\
\hline & Participation activities $(n=9)$ & $\begin{array}{l}\text { Additional participation opportunities }(n=5) \\
\text { Activity that the whole family can become involved with } \\
(n=3) \\
\text { Desire to compete (SSGO) }\end{array}$ \\
\hline & Contact $(n=4)$ & $\begin{array}{l}\text { Information about club and future participation } \\
\text { opportunities }(n=3) \\
\text { Ability to contact student participants (SSGO) }\end{array}$ \\
\hline & Other $(n=2)$ & $\begin{array}{l}\text { Children being older and having more control over choices } \\
(n=2)\end{array}$ \\
\hline \multirow[t]{6}{*}{ Barriers $(n=21)$} & Expense $(n=9)$ & $\begin{array}{l}\text { Participation/membership costs and cost of travel to club } \\
(n=8, \text { SSGO })\end{array}$ \\
\hline & Interest $(n=3)$ & $\begin{array}{l}\text { Clubs not interested in contacting program participants } \\
\text { (SSGO) } \\
\text { Club receptiveness to new members (SSGO) } \\
\text { Some clubs do not need additional/new members (SSGO) }\end{array}$ \\
\hline & Contact $(n=3)$ & $\begin{array}{l}\text { Interested people not following up and contacting club } \\
\text { (SSGO) } \\
\text { Inability of the club to directly contact program } \\
\text { participants (SSGO) } \\
\text { Privacy laws (SSGO) }\end{array}$ \\
\hline & Locality $(n=2)$ & Proximity to sport club $(n=2)$ \\
\hline & Parents $(n=2)$ & $\begin{array}{l}\text { Parents not exposed to child's participation in the sport } \\
\text { through the introductory program }(n=2)\end{array}$ \\
\hline & Other $(n=2)$ & $\begin{array}{l}\text { Ability for people to participate in the sport without having } \\
\text { to become club members (SSGO) } \\
\text { Other school-based opportunities to participate in the } \\
\text { sport (SSGO) }\end{array}$ \\
\hline
\end{tabular}


The SSGO randomly selected for in-depth investigation reported that it conducted its school-based program in a way that encouraged local communitybased clubs to deliver the program. This strategy was implemented to increase the capacity of the sport to reach more students to raise students' awareness of community-based clubs, and to increase the likelihood of the clubs securing additional memberships. SSGOs also increased the capacity of the program by training teachers to deliver the program in their schools. However, there were no specific strategies in place to integrate or link schools and clubs.

Table 2 provides a summary of the reported facilitators and barriers to linking the school-based program experience and club membership. The responses by the SSGO are indicated, and those by teachers and/or parents $(n=8)$ are represented by the number stating the particular issue.

\section{Discussion}

This study found an absence of formal links between school-based sports programs and local community sporting organisations despite the stated objective being to promote community-based sports participation. Despite this absence, it was apparent that common themes facilitating uptake of sport club membership by participants in the school-based programs included an interest in continued participation by participants, and the desire from local clubs to have more members. Conversely, lack of interest acted as a barrier.

Teachers and parents suggested strategies such as invitations to school-based participants to engage in repeated or additional experiences in the sport at the community club along with providing the students with general information about the local club. Further, given the impact of parental influences on children's choice of a given sport, many parents and teachers felt that the presence of parents at an introductory club session would facilitate their knowledge of the sport and if coupled with their child's enjoyment would encourage engagement in a local club.

A key barrier to the establishment of a more efficient and effective structural link between school and club-based sport appears to be the general lack of interest by SSGOs in promoting the transfer of school-based participants into their clubs. Many of the SSGOs interviewed saw school-based programs only fulfilling a general promotional purpose, and viewed the programs as being ineffective for facilitate continued participation and club membership. Further, it appeared that the SSGOs were conducting school-based programs in order to fulfil an obligation to the funding body. In cases where school-based programs were provided by local volunteers, these programs appeared to be conducted reluctantly, and out of a sense of obligation to the local children in the face of a perceived deficiency in the capacity or willingness of the state-based education system to provide such programs.

School-based programs are often delivered using a 'one-size-fits-all' approach. That is, the programs are delivered to clubs and/or schools with little or no acknowledgement of the context in which the programs are presented and in the absence of links between schools and community-based clubs. Further, in many instances, sports organisations worked in isolation from each other. The isolation also works in reverse, whereby schools often offered sport programs that are not integrated into local community or state-wide networks. In general, the isolation that these organisations experience appears to have occurred because each organisation works towards their specific organisational goals and meeting funding body objectives, unaware of other similar organisations working in the same way.

In general, it is apparent that the school-based sports programs are delivered in a manner that is not integrated into the broader community context and therefore have little chance of promoting sustained community level change. ${ }^{24}$ From a health promotion perspective, these programs should be broadened to include both the current individual focus along with the development of sustainable structures or environments and in doing so to involve key community stakeholders in the development and implementation process. ${ }^{24}$

There is a need for innovative approaches to health promotion which will encourage adolescents to maintain participation in physical activity once they leave school. ${ }^{7}$ An approach to developing long-term community engagement in sport and a potentially more sustainable model for sports organisation delivered school sport participation programs would be to adopt a tailored approach. This needs to be developed within a common developmental framework based on recognised health promotion planning principles including collaborative work that increases empowerment and community competence to determine and meet their needs and desires. ${ }^{25,26}$ Whilst there are examples of strategies to link schools and community-based physical activity programs in the peer-reviewed literature, ${ }^{4}$ none were found specific to sport. One paper provides 10 recommendations for school and community programs specifically in the promotion of physical activity 
amongst the young children. ${ }^{4}$ The broad headings for the recommendations are: policy, environment, physical education, health education, extracurricular activities, parental involvement, personnel training, health services, community programs and evaluation. For any successful integration of schoolcommunity physical activity programs each of these areas need to be considered. ${ }^{4}$

One model for enhancing sport links between schools and sports focuses upon achieving community change to build healthier communities. The model is comprised of five components: community context and planning; community action and intervention; community and systems change; risk and protective factors and widespread behaviour change; and improving more distant outcomes (the long-term goals). ${ }^{27}$ This model encompasses community capacity building and specific partnership strategies, which are generally promoted as a means of building a more cohesive approach to sport by schools and sports organisations. $6,9,11,28,29$ The majority of these authors advocate partnership development between schools and local clubs to facilitate participation in sport and physical activity, and they provide examples of the school acting as the facilitator. The School-Community Links Model is one example of a partnership approach with instructions on how schools can establish links with the community. ${ }^{9}$ Strategies for the school include: conducting a needs assessment; developing links with the broader community; and specific strategies that facilitate the establishment of the school-club link. One template, developed by a Junior Sport Reference Group in Victoria, suggests that SSGOs should take the lead role in the school-sport partnership when trying to develop sustainable school-club links. ${ }^{30}$

Whilst this study employed multiple methods to provide a comprehensive understanding of sports organisation-delivered programs. However, in school settings, there are limitations, in particular to the in-depth program evaluation. Only one program was investigated in depth and this investigation was limited to six schools. The results for this particular program are not generalisable to all sports organisations, or to all programs delivered in a school-setting. This study relies on data from teachers and parents and not children. However, it is apparent that the teachers and parents were knowledgeable informants in this case.

\section{Conclusion}

In general, it is recommended that sports organisations use recognised health promotion planning principles to deliver school-based sport programs to enhance the transfer of participants into their community clubs. It is proposed that funding bodies should promote this approach, and in doing so build the capacity of the sports organisations to understand health promotion and develop as health promotion organisations. Some specific recommendations are to adopt collaborative approaches between sports organisations, local club(s), and local schools to identify participant needs, and to adopt flexible approaches to program delivery in order to cater for these needs. The best mechanism for communicating between the school, participants, participant parents and local clubs needs to be identified and implemented. In particular, exposure of parents to the child's initial involvement has been identified as an important factor that affects the likelihood of continued participation. It is recommended that where applicable, sports organisations alter their program focus within a school-based setting from a 'one-size-fits-all' approach to a tailored approach implemented from a common framework based upon health promotion program planning principles. This will require the development of specific strategies for different schools and communities and will have significant resource implications due to increased demands on time and human resources. It is therefore suggested that sports organisations pilot this approach so as to develop effective operational frameworks and to determine the cost-effectiveness of this approach. It is concluded that this approach will enable sports organisations and clubs to benefit from the development of sustainable school-based participation programs and ultimately facilitate club membership. In addition, the children and youth participants will benefit by access to opportunities to continue participating in health enhancing sporting activities.

\section{Practical implication}

- Sports bodies should incorporate health promotion strategies into their school-based programs in order to establish and maintain schoolcommunity links.

\section{Acknowledgements}

This study was funded by VicHealth as a component of the VicHealth Sport and Active Recreation Schemes Evaluation Project. Staff from VicHealth are thanked for their overall contribution to the administration of this research. We thank the SSGO 
staff, school teachers and parents of program participants for their contribution to this project. Jack Harvey is thanked for his expertise with the web-based survey design.

\section{References}

1. National Public Health Partnership. Be active Australia: $a$ framework for health sector action for physical activity. Melbourne: NPHP; 2005.

2. Taggart A, Sharp S. Junior sport vision: looking back to look forward to the new millennium? 2000. Perth: Sport and Physical Activity Research Centre, School of Education, Edith Cowan University; 2000.

3. Ross A, Coghlan K. Health for all, forever: what is the future for health promotion? VicHealth Lett 2005;25(Winter):8-9.

4. US Department of Health and Human Services. Guidelines for school and community programs to promote lifelong physical activity among young people. MMWR 1997;46(RR6): $1-36$.

5. Wright J, Macdonald D, Groom L. Physical activity and young people: beyond participation. Sport, Educ Soc 2003;8(1):17-33.

6. Australian Sports Commission and State Departments of Sport and Recreation and Education. Schools and clubs: Ideas for working together. Canberra: Australian Sports Commission; 1994.

7. Dovey S, Reeder A, Chalmers D. Continuity and change in sporting and leisure time physical activities during adolescence. Br J Sports Med 1998;32(1):53-7.

8. Bauman A, Bellow B, Vita P, et al. Getting Australia active: towards better practice for the promotion of physical activity. Melbourne: National Public Health Partnership; 2002.

9. Patterson I. Encouraging participation in physical activity through school and community links. ACHPER Healthy Lifestyles J 1999;46(4):17-23.

10. Taggart A, Sharp S. Adolescents and sport: determinants of current and future participation. Perth: Sport and Physical Activity Research Centre, Edith Cowan University; 1997.

11. Tomson L, Patterson I, Cuskelly G, et al. Promoting physical activity, sport and recreation through school and community links. Brisbane: Griffith University; 1997.

12. Gray S. Team clubs sports clubs for adults: a model. Am Assoc Behav Soc Sci Online J 2004;7:44-8.

13. Wigger U. Exercise and youth: physical activity, sport involvement, and development. Eur J Sport Sci 2001;1(3).

14. Zeldin S. Preventing youth violence through the promotion of community engagement and membership. J Community Psychol 2004;32(5):623-41.
15. Thomson S. Engaging students with school life. Youth Stud Aust 2005;24(1):10-5.

16. Allen J. Social motivation in youth sport. J Sport Exerc Psychol 2003;25:551-67.

17. Clough J, McCormack C, Traill R. A mapping of participation rates in junior sport. ACHPER Natl J 1993;40(2):4-7.

18. Giles-Corti B, Donovan R. The relative influence of individual, social and physical environment determinants of physical activity. Soc Sci Med 2002;54:1793818.

19. Tammelin T, Nayha S, Hills A, et al. Adolsecent participation in sports and adult physical activity. Am J Prev Med 2003;24(1):22-8.

20. Aaron D, Storti K, Robertson R, et al. Longitudinal study of the number and choice of leisure time physical activities from mid to late adolescence: implications for school curricula and community recreation programs 2002;11:1075-80.

21. VicHealth. Strategic directions 2003-2006. Melbourne: VicHealth; 2002.

22. Eime R, Payne W, Harvey J. VicHealth sport and active recreation schemes evaluation report: volume one: partnerships for health scheme. University of Ballarat; 2006.

23. Miles M, Huberman M. Qualitative data analysis. Second edition Thousand Oaks: SAGE Publications; 1994.

24. Inchley J, Muldoon J, Currie C. Becoming a health promoting school: evaluating the process of effective implementation in Scotland. Health Promot Int 2006;22(1):65-71.

25. Department of Human Services. Integrated health promotion resource kit. Melbourne: State Government of Victoria; 2003.

26. Minkler M. Improving health through community organizations. In: Glanz K, Lewis F, Rimer B, editors. Health behavior and heath education: theory, research and practice. San Francisco: Josey Bass; 2002.

27. Work Group on Health Promotion and Community Development. Our model of practice: building capacity for community and systems change. http://ctb.ku.edu/ tools/en/sub_sectoin_main_1002.htm [accessed September 2006].

28. Bynum M. Shared destinies: combined high school/ community recreation centers can offer their populations distinct benefits, but they must first overcome the inevitable scheduling and programming challenges. Athl Bus 2003;27(5):70-2.

29. Department of Sport and Recreation Western Australia. PasSport into schools: linking sports with schools. Perth: Department of Sport and Recreation; 2003.

30. VicSport. School club links. http://www.vicsport.asn.au/ content.asp?contentID=174\&topic_ID=540; 2006 [accessed September 2006]. 